\title{
Availability, And Awareness of Non-Pneumatic Antishock Garment in Tertiary Hospitals of Northern Nigeria.
}

\author{
*Umar A.B ${ }^{1}$., Ogwu T.N². And Chado M.A ${ }^{2}$ \\ ${ }^{1}$ Department Of Nursing Science Ahmadu Bello University Zaria \\ ${ }^{2}$ Department Of Physical And Health Education Ahmadu Bello University Zaria
}

\begin{abstract}
:
Background: The (NASG) was introduced as a gadget that can be used for first aid treatment of women in postpartum shock prior to proper investigation and appropriate management of the patient.

Purpose of the study: aims at assessing the availability, awareness and utilization of non-pneumatic Antishock garment in tertiary hospitals of Northern Nigeria. That is the North West, North East and North central.

Materials and methods: A descriptive design was used .Isaac \& Michael, (1981); Smith, (1983) sample size chart revealed that for a given population of 100,000 and above the sample size for such population should be 398. A four point level likert scale questionnaire was structured. The data collected was analysed using one way analysis of variance (ANOVA) and with a 0.05 level of confidence to answer the hypotheses. A constant mean of 2.5 was used to ascertain the agreement of the respondents on the questionnaire items.

Results of the study, revealed that, NASG is available in the selected hospitals but strictly within the control of the hospitals' management in Northern Nigeria with an aggregate mean score of 2.32 .Nurses and doctors in tertiary hospitals in Northern Nigeria are aware of the NASG for postpartum haemorrhage with an aggregate mean score of3.18. There is significant difference in the availability and awareness of the NASG for postpartum haemorrahage among nurses and doctors of the selected tertiary hospitals in Northern Nigeria.

Conclusion: the NASG is available strictly in tertiary hospitals in Northern Nigeria and doctors and nurses are aware of it.
\end{abstract}

Keywords: Availability, Awareness, Non-pneumatic Anti-shock garment, Tertiary hospitals, Northern-Nigeria

\section{Introduction}

Postpartum haemorrhage ( $\mathrm{PPH})$ is the single largest cause of maternal death worldwide accounting for one third (1/3) of all deaths (WHO, 2010) and these deaths are largely preventable with skilled attendance and comprehensive emergency obstetric care (WHO, 2010). A woman suffering from PPH can die within two hours unless she receives immediate and appropriate medical care. The identification of complications and the decision to take a woman to a health facility is delayed and transportation may not be available (MouradYoussif etal,2010). When a woman suffering from postpartum haemorrhage arrives at a health facility and there are no trained staffs, essential supplies or medications available to treat her and this places her life in danger or at risk of dying (McCarthy, \&Maine, 1992).

Management of postpartum hemorrhage requires identifying the cause of haemorrhage, replacing the fluids to prevent shock, using an appropriate uterotonics, applying the Non-pneumatic anti-Shock garment (NASG) when shock occurs, replacing blood and performing surgery(pathfinder, 2007).

Non-pneumatic anti-Shock garment (NASG) is a key component of managing hypovolemic shock and is ensuring that the available blood in the body is directed mostly to the upper parts of the body so that vital organs continue to receive oxygen. The woman is protected from vital organ damage or death (pathfinder, 2007). This can be achieved by applying Non-pneumatic anti-shock garment (pathfinder, 2007).The Nonpneumatic anti-shock garment is a first-aid device that reverses hypovolemic shock and decreases obstetric haemorrhage. It consists of articulated neoprene segments that close tightly with Velcro, shunting blood from the lower body to the core organs, elevating blood pressure and increasing preload and cardiac output (Miller,etal, ,2008). The abdominal segment incorporates a small foam ball that applies pressure to the uterus to decrease bleeding. Unlike the pneumatic anti-shock trousers (PAST), or medical anti-shock trousers (MAST), which preceded the NASG, there are no pumps, tubing, or gauges to add complexity and risk of malfunction. Using the three-way elasticity of neoprene and the tight grip of the Velcro fasteners, the garment can apply 30 $40 \mathrm{mmHg}$ of circumferential counter pressure to the lower body from the ankles up to the level of the diaphragm. NASG is an efficient, simple and a safe means to apply external counter pressure to the lower body. It aids resuscitation of central circulation through translocation of up to $30 \%$ of the total blood volume from the lower body to the chest and head. Also reduces hemorrhage in lower body by ensuring a decrease in arterial perfusion pressure to the uterus. The pressure in the capillary and venous system (15-25 $\mathrm{mm} \mathrm{Hg}$.) is overcome, leading to reduction of transmutably pressure, vessel radius and flow. This stabilizes patient while evaluating, 
transporting or preparing for definitive surgical treatment in the hospital (Hensleigh, 2002). With proper monitoring, NASG can be safely and comfortably used for 24 - 48 hours. Use of anti shock garment does not avert the necessity for evaluation to identify cause of shock, management of fluid and blood replacement, and appropriate therapy for coagulopathy (Hensleigh, 2002). Criteria for applying NASG include Blood loss of $750 \mathrm{ml}$ or more ( in many cases, blood loss less than 750 with signs of compromised circulation or poor clinical state of patient can be included), Pulse rate of 100 or more/ min, systolic blood pressure of less than $100 \mathrm{~mm} \mathrm{Hg}$, and Shock (Miller,etal., 2008) . Studies on NASG by Ojengbede (2006), where conducted in Lagos and Oyo states to test the effectiveness of the NASG for use in cases of obstetric haemorrhage in Nigerian referral hospitals, and the results revealed that NASG reduces blood loss, mortality, and morbidity. The results also demonstrated, $60 \%$ decrease blood loss, $60 \%$ decrease in mortality and $85 \%$ decrease in morbidity (Ojengbede, 2006). The result of studies by miller, etal. (2010) revealed that, there were significantly fewer women in the NASG phase receiving either $>1500 \mathrm{ml}$ crystalloid fluids or a blood transfusion in the first hour. Volumes of blood loss after study entry were lower (Bressa, Hensleigh, and Peligra, 2004).

Maternal mortality is a major problem worldwide. Globally, 287,000 annual maternal deaths are recorded worldwide, $56 \%$ occur in sub-Saharan Africa a region that accounts for only $21 \%$ of the world population. India and Nigeria account for one third of the global maternal mortality. Maternal mortality rate in Africa is the highest in the world, and it is estimated at 500 deaths per 100, 000 live births (WHO, UNICEF, UNFPA \& World Bank, 2012). The risk of maternal death in Nigeria is 1:29 compared to 1: 25000 in Greece a develop country (WHO, UNICEF,UNFPA \& World Bank ,2012). Women in developing countries are more than 15 times more likely than women in developed countries to die in childbirth (USAID, 2010). Even within developing countries there is a striking differential risk of maternal death for women who have access to basic essential obstetrical care compared to those who do not. Within a country, as poverty increases so does the proportion of women dying of maternal causes (USAID, 2010). Nigeria constitutes $2 \%$ of world's population but contributes $14 \%$ of the global estimates of maternal deaths (WHO, UNICEF,UNFPA \& World Bank,2012). Nigeria has the most alarming record of maternal mortality, second to India throughout the developing world (WHO, 2010). It is estimated that about 40, 000 women die as a result of pregnancy complication and child delivery in Nigeria (WHO, UNICEF, UNFPA \& World Bank,2012).Like in many developing countries, women in Nigeria do not have access to good quality health services during pregnancy and child birth, especially those who are poor, uneducated or who live in rural areas. Most maternal deaths takes place during and soon after child birth, which can be attributed to the fact that less than half of women in Nigeria get adequate health care during, these periods (WHO, 2010).

\section{Availability of the non-pneumatic antishock garment}

The Non-pneumatic anti-shock garment is available in many sizes as can be seen below:

\section{1) Small - Burgundy}

This size is meant for people of thin and small stature.

Generally fits people four feet tall or less, and about $36.3 \mathrm{~kg}$ or less.

\section{2) Regular - Black}

This size is meant to be one size fits "All". Generally fits people between 1.1 meter to 1.6 meter tall, and between $36.3 \mathrm{~kg}$ and $99.8 \mathrm{~kg}$. Regular can be used on children, when short, just simply fold up section \#1 over (or into) section \#2, then apply as usual starting with section \#2.

\section{3) Large - Blue}

This size is meant for larger people, big frame and large girth. Approximately $113.4 \mathrm{~kg}$ and up. The height ratio is the same as in the regular(1.1meter to $1.6 \mathrm{~meter})$. If the patient is over 1.63meter or more, it would take a little application adjustment. The Non-pneumatic anti-shock garment is not yet available in the open market, but designated health centers through the efforts of government and pathfinder international. (Ojengbede ,etal.,2008)

\section{Awareness of non-pneumatic anti-shock garment}

Oshonowo (2007) in pathfinder (2011) suggested that, media should be used to increase community awareness of the non-pneumatic anti-shock garment (NASG).Because providers in most health centers have limited capacity, Pathfinder concentrates on training and equipping secondary and tertiary facilities where most crisis cases first appear. Interest in the model is also growing among private sector doctors, who provide 30 percent of deliveries (Wilder, 2009).Health institutions were also train so as to step down training to their students during training periods. 


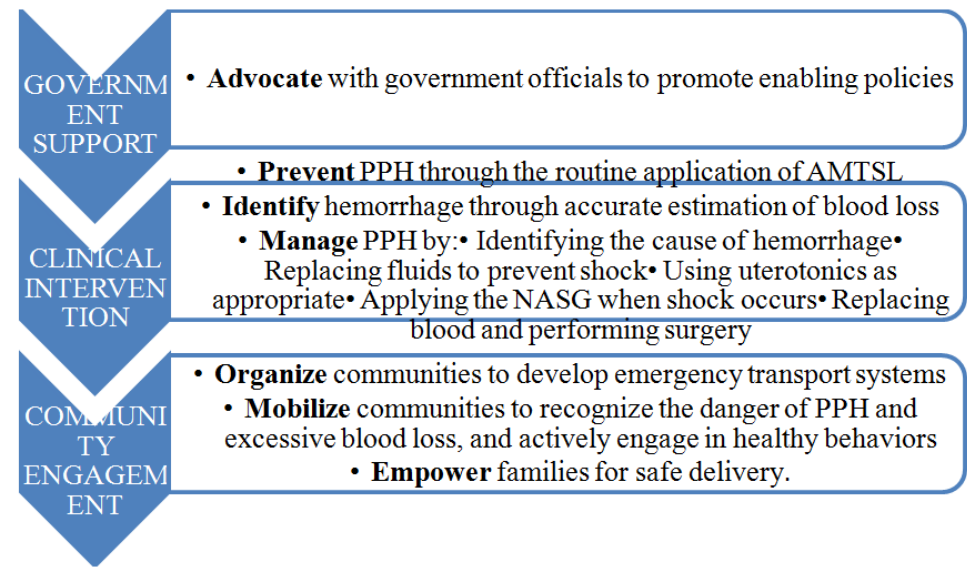

Figure 1: Pathfinder international's community and clinical action to address postpartum hemorrhage approach (Pathfinder international's (2011)

Pathfinder's Community and Clinical Action to Address Postpartum Hemorrhage (CCA-PPH) has the following actions in view: (1)Increase awareness among community members and providers of the danger signs of PPH and the ability of project technologies like NASG to prevent and manage PPH; (2) Improve capacity of community members to make timely decisions to seek medical care for PPH; (3) Increase ability of community members to identify and reach facilities for PPH treatment; and (4) Improve capacity of health care providers to provide high-quality, timely, and appropriate care to women with PPH. In support of these objectives, Pathfinder's Community and Clinical Action to Address Postpartum Hemorrhage (CCA-PPH) approach incorporates prevention, recognition, and treatment of PPH, including standard methods for estimating blood loss, the non-pneumatic anti-shock garment (NASG) awareness, community-level engagement, and advocacy regarding the need for a continuum of care. Pathfinder has implemented activities in 60 facilities and 42 communities in seven states of Nigeria (Kano, Katsina, Oyo, Lagos, Nasarawa, Ebonyi, and Yobe (Pathfinder, 2011).

\section{Effectiveness of the Non-Pneumatic Anti-Shock Garment (NASG)}

Within 2-5 min after its application, most patients with severe shock regain consciousness and vital signs begin to recover. With the bleeding slowed and the blood the pressure restored, panic levels decrease, and there is time to deliberately assess the situation (Miller, 2008). Bressa et al., (2004), reported that, the Nonpneumatic anti-shock garment (NASG) outcome include (a) decreased blood loss due to obstetric hemorrhage, (b) fewer emergency hysterectomies, and (c) more rapid recovery from shock. The results of studies by miler, et al. (2010), reveals that, treatment variables show significantly fewer women in the NASG phase receiving either $>1500 \mathrm{ml}$ crystalloid fluids or a blood transfusion or volumes of blood loss .Emergency hysterectomies for intractable uterine atony were reduced by $56 \%$, Severe morbidities were decreased by $81 \%$, mortalities were reduced by $44 \%$. The effectiveness of the NASG in reducing blood loss and time to recovery from shock was initially shown in pilot studies in Egypt. Larger pre-post studies in Egypt and Nigeria indicate that NASG use can significantly reduce maternal mortality and extreme adverse outcomes (EAO) (maternal death or severe maternal morbidity). In Nigeria, the relative risk (RR) of mortality in the NASG intervention phase, compared to the pre-intervention phase was 0.32 (95\% confidence interval [CI] 0.14-0.72), and in Egypt, the RR of EAO with the NASG was 0.36 (95\% CI 0.16-0.80), (Miller, et al., 2010). The NASG can make a significant contribution to help women with PPH survive delays, even when the delays are experienced before NASG application. The results of this analysis indicate that at the referral facility level, the NASG can stabilize women suffering from obstetrical hemorrhage and hypovolemic shock and help them survive delays in obtaining treatment. It appears that the NASG has the biggest impact in settings where delays in obtaining treatment are lengthy.

\section{Statement Of Problem}

Hemorrhage is the leading direct cause of maternal deaths in the world-every year 132,000 women bleed to death while giving birth, that is $46 \%$ of deaths globally( USAID,2011). Globally, a woman dies every seven minutes from the PPH. PPH is commonly defined as loss of $>500 \mathrm{~mL}$ of blood during the first day postpartum; severe PPH is loss of $1000 \mathrm{~mL}$ or more. However, quantifying blood loss is difficult and, even in a clinical setting, amounts are generally underestimated (USAID, 2011). These deaths can be prevented with skilled attendance, comprehensive emergency obstetric care and use of simple technology like the anti-shock garment (WHO, 2010). Most women die of haemorrhage in resource setting due to delay in the circulatory 
volume, getting timely and adequate blood /fluid replacement, thus, leading to hypovolemic shock or death (Miller,etal.,2007). Ijaiya,Aboyeji \& Abubakar, (2003) reported an incidence of 4.5\% for postpartum haemorrhage in Ilorin. Jadesimi \&Okonofua ( 2006), reported astudy carried out in a hospital in Kano, Northern Nigeria which revealed an astonishing MMR of 7,523 per 1001000 live births. The results of a study by Kullami ,Kawuwa, Audu,Geidam, \&Mairiga, (2009), in a tertiary hospital in Northern Nigeria (FMC Nguru) revealed that ,the maternal mortality ratio (MMR) was 2849/100,000 deliveries. Postpartum haemorrhage (PPH) contributing 17\%. In 2006, the Joint Statement of the International Confederation of Midwives (ICM) and the Federation International of Gynaecology and Obstetrics (FIGO) recommended research on Antishock garments to reduce mortality among women suffering from postpartum hemorrhage (ICM/FIGO, 2010).

\section{Purpose Of The Study}

The main purpose of this study is: to assess the availability and awareness of the Non-pneumatic antishock garment in the tertiary hospitals of Northern Nigeria.

The specific purposes are:-

1. To assess if the Non-pneumatic anti-shock garment is available in the tertiary hospitals of Northern Nigeria.

2. To assess whether doctors and nurses in tertiary hospitals of Northern Nigeria are aware of the Nonpneumatic anti-shock garment.

3. To asses if there is any difference in the availability, awareness, and utilization of the Non-pneumatic

Anti- shock garment on postpartum Haemorrhage among the tertiary hospitals in the Northern Nigeria.

\section{Research Questions}

1.Is the Non-pneumatic anti-shock garment available in tertiary hospitals of Northern Nigeria?

Are the doctors and nurses in tertiary hospitals in Northern Nigeria, aware of the Non-pneumatic anti-shock garment?

2.Is the Non-pneumatic anti-shock garment used in tertiary hospitals of Northern Nigeria?

3. Is there any difference in the availability, awareness and utilization of the Non-pneumatic anti-shock garment among the tertiary hospitals of the Northern Nigeria?

\section{Significance Of The Study}

The result of the study will be useful in the following ways:-it will

i. Provide information for health care providers on the vital role of Non-pneumatic anti-shock garment in preventing obstetric shock due to PPH.

ii. Motivate the government to supply the garments in the health care settings.

Iii Inform health care planners to develop policies that will ensure availability of the Non-pneumatic anti-shock garments in hospitals of Northern Nigeria.

\section{Major Hypothesis}

There is no significant difference in the availability and awareness of Non-pneumatic anti-shock garment on postpartum haemorrhage in tertiary hospitals of Northern Nigeria.

Sub-Hypothesis I There is no significant difference in the availability of Non-pneumatic anti-shock garment among the tertiary hospitals of the Northern Nigeria.

Sub-hypothesis Il There is no significant difference in the awareness of Non-pneumatic anti-shock garment in Northern Nigeria.

\section{Research Design}

A descriptive design was used for the study. The information required to assess the availability, awareness, utilization and effectiveness of non-pneumatic anti-shock garment on postpartum haemorrhage in Northern Nigeria already exist and without manipulation of the variables by the researcher. Therefore, ex-post facto research design is used. Kenlinger (1986) stated that this design is the best tool in descriptive research involving current events or conditions.

\section{Study Population}

The population of this study consists of doctors and nurses in each of the three geopolitical zones of Northern Nigeria. This includes North East with 6 states, North West with 7 states and North Central with 6 states including FCT Abuja. However, these zones consist of 105,510 doctors and nurses (WHO \& GHWA, 2008). 


\section{Sample Size And Sampling Technique}

For the purpose of this study, a sample size of 398 respondents was use. This is in accordance with the sample size chart of Isaac \& Michael, (1981); Smith, (1983) who reported that for a given population of 100,000 and above, the sample size for such population could be 398 .Sampling techniques to be use are stratified random and purposively sampling technique. In these techniques, all the existing states in Northern Nigeria in stratified into the three geopolitical zones, which are: North East - Adamawa, Borno, Taraba, Gombe, Bauchi, and Yobe States; North West - Kebbi, Sokoto, Zamfara, Kano, Katsina kaduna, jigawa and North Central Nasarawa, Benue, Kwara, Plateau, FCT Abuja, Kogi and Niger States. Each of these three geopolitical zones constitutes a stratum. In this selection, all the States were given numbers from which two (2) states were picked by employing dip and pick method (Nworgu, 1991). Also from each randomly selected state, one tertiary hospital were selected purposefully, where there are more than one tertiary hospital in a state, one tertiary hospital were randomly selected. Hence, a total of six (6) States, six tertiary hospitals of which three hundred and ninety eight (398) respondents were purposefully sampled from labour ward, postnatal ward, gynae ward, antenatal, emergency ward and gynae outpatient department to serve as respondents for this study at a ratio of $1: 4$ doctors and nurses.

\section{Instrumentation}

The instrument used for this study is the questionnaire. The questionnaire contains 3 sections A to C. Section A consists statements on demographic characteristics; Section B consists of seven statements on availability, Section C consists of seven statements on awareness, of non-pneumatic anti-shock garment. A four points likert scale which is an interval scale of measure, that is, strongly agree, agree, disagree and strongly disagree was used to structure responses for the respondents.

\section{Validation Of The Instrument}

Five (5) copies of the questionnaire were given to five (5) jurors. Four experts from the Department of Physical and Health Education of Ahmadu Bello University Zaria and the fifth juror was from the department of obstetrics and gynaecology, Ahmadu Bello University Teaching Hospital Shika, Zaria, in order to ascertain both content and face validity of the instrument. After incorporating all the suggestions made by the jurors, the final questionnaire was prepared for a pilot study.

\section{Administration Of Instrument}

The researcher obtained letter of introduction from the Department of Physical and Health Education, Ahmadu Bello University, Zaria to the tertiary hospitals under study to conduct research on assessment of the availability, awareness of non-pneumatic anti-shock garment on postpartum haemorrhage in Northern Nigeria, from which ethical approval was obtained. The researcher, six recruited research assistants trained in details on how to administer and collect the research instrument to and from the respondents. Respondents were purposefully drawn from labour ward, postnatal ward, gynae ward, antenatal, emergency ward and gynae outpatient department to serve as respondents for this study at a ratio of 1:4 doctors and nurses.

\section{Statistical Techniques}

The data collected was collated, coded and analysed. The Statistical Package for Social Science (SPSS PC package) was used for the data analysis. Descriptive statistics of frequencies, percentages, mean and standard deviations were computed. The scores were subjected to one way analysis of variance (ANOVA). This is in accordance with the suggestion of Roscoe (1969) who suggested that for a study that uses an interval level of measure, looking for difference from two or more groups which are independents of one another, ANOVA is the basic analysis technique. Multiple comparative analysis were use to test the hypotheses at an alpha level of 0.05 . A constant mean of 2.5 was used to ascertain the agreement or disagreement of respondents to the questionnaire items.An aggregate mean score of less than 2.5 indicate the absence of non-pneumatic Antishock garment (NASG), a lack of awareness, lack of utilization of non-pneumatic Antishock garment (NASG) in the facility and non-effectiveness of the non-pneumatic Antishock garment on postpartum in the facility. While an aggregate mean score of 2.5 and above indicate the availability of non-pneumatic Antishock garment (NASG), awareness, utilization of non-pneumatic Antishock garment (NASG) in the facility and effectiveness of the nonpneumatic Antishock garment on postpartum in the facility.

\section{Results And Discussion}

398 questionnaires were administered through purposeful sampling technique and 375 (94\%) were returned. The data collected in responses to statements related to availability and Awareness, of non-pneumatic Antishock garment (NASG) in tertiary hospitals in Northern Nigeria were statistically analyzed in this chapter. The results are presented below: 
Table 1. Demographic characteristics of the respondents

\begin{tabular}{llcc}
\hline Variables & Variable option & Frequencies & Percentage \\
\hline Age in years & $19-24$ & 6 & 1.6 \\
& $25-29$ & 61 & 16.3 \\
& $30-34$ & 139 & 37.1 \\
& $35-39$ & 94 & 25.1 \\
& $40+$ & 75 & 20.0 \\
& Total & $\mathbf{3 7 5}$ & $\mathbf{1 0 0 . 0}$ \\
\hline Gender & Male & 113 & 30.1 \\
& Female & 262 & 69.9 \\
& Total & $\mathbf{3 7 5}$ & $\mathbf{1 0 0}$ \\
\hline & Nurses/midwives & 297 & 79.2 \\
& Doctor & 78 & 20.8 \\
\end{tabular}

Table 1. shows the demographic characteristic of the respondents at observation of the table.

The subjects were concentrated in the 30 to 34 years age $(37.1 \%)$ with only 6 or $1.6 \%$ within 19 and 24 years and 61 or $16.3 \%$ between 25 and 29years. And 94 or $25.1 \%$ were between 35 and 39years while 75 or $20.0 \%$ were above 39years. Of the total number of the respondents, 113 or $30.1 \%$ were male and 262 or $69.9 \%$ were female. Of the overall total in terms of designation, 297 or $79.2 \%$ were Nurses while the remaining 78 or $20.8 \%$ were medical doctors. These two groups constituted the main focus of the investigation of the subject because of their vintage positions in the hospitals.

Table 2. Mean and standard deviation scores by the respondents on availability of NASG $\mathrm{N}=375$

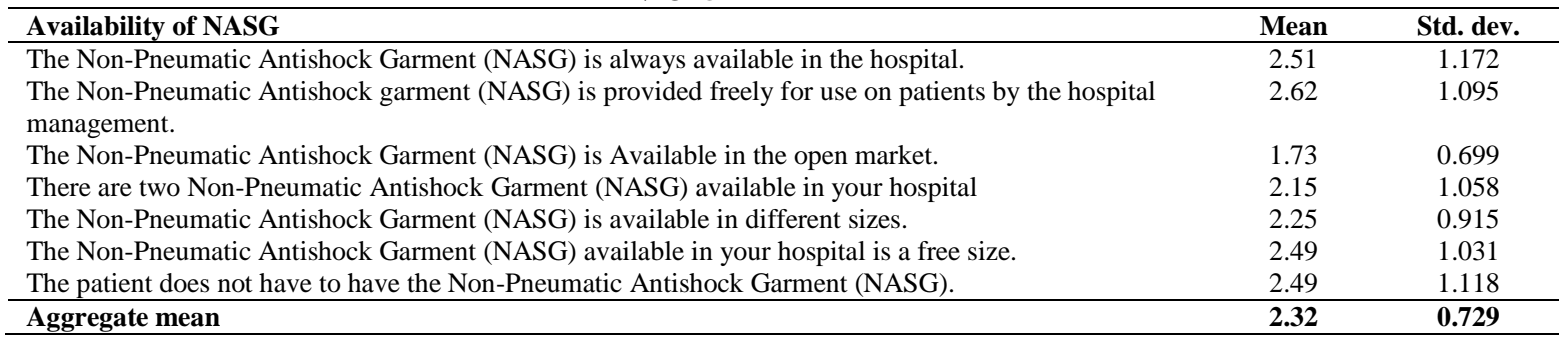

Table 2. above shows an aggregate mean score of 2.32; this is more a generalization of the availability of the Non-Pneumatic Antishock Garment in the wider society than in the selected hospitals. This fact is attested to by the mean score for item 1 which is 2.51 where the availability of the garment was measured in the hospitals. A further confirmation of their availability in the hospitals is seen in the mean score of 2.62 for the second item where the respondents agreed that the Non-Pneumatic Antishock garment (NASG) is provided freely for use on patients by the hospital management. However, they did not agree that the garment is available in the open market. The mean score of 1.73 for this item contributed to the low magnitude of the aggregate mean. Moreover, the respondents did not agree that there were two Non-Pneumatic Antishock Garments (NASG), available in the hospitals and they did not agree that the garments were available in different sizes. These series of disagreement accounted for the low aggregate mean. In other words, the NASG could not be said to be generally available but restricted to the administration of the hospital management who are in position to dispense it according to their dictates. This accounted for the observed non-availability of the garment in any other places.

Table 3. Mean and standard deviation scores on awareness of NASG by the respondents $\mathbf{N}=\mathbf{3 7 5}$

\begin{tabular}{lcc}
\hline Awareness of NASG & Mean & Std. dev. \\
\hline The Non-Pneumatic Antishock Garment is a light weight washable and inexpensive garment. & 3.03 & 0.257 \\
The Non-Pneumatic Antishock Garment is stretchable & 3.31 & 3.51 \\
The Non-Pneumatic Antishock Garment is a device for resuscitating patient from shock & 3.43 & 0.674 \\
Every health care personnel should know about the use of the Non-Pneumatic Antishock Garment & 0.713 & 2.63 \\
(NASG). & 0.761 \\
You have had training on the Non-Pneumatic Antishock Garment (NASG). & 3.23 \\
When applied on a patient, the Non-Pneumatic Antishock Garment applies a circumferential pressure. & 0.751 \\
A patient with the Non-Pneumatic Antishock Garment (NASG) on can undergo any investigation to find & 3.14 \\
\hline out the cause of the haemorrhage. & 0.841 \\
\hline Aggregate mean & $\mathbf{3 . 1 8}$ \\
\hline
\end{tabular}

Table 3. Above showed an aggregate mean score of 3.18 for awareness of the Non-Pneumatic Antishock Garment .This means a consensus agreement among the respondents that the level of awareness of 
the garment in the hospital was very high. To further confirm this agreement, there was none of the items on awareness that was scored below 2.60.This means that the respondents could be said to have generally agreed that there is high level of awareness of the NASG for postpartum haemorrhage in the hospitals.

\section{Major Hypothesis:}

There is no significant difference in the availability and awareness of NASG on PPH in tertiary hospitals of Northern Nigeria.

To test this hypothesis, one way analysis of variance (ANOVA) was used and. This hypothesis was tested by the aggregate mean scores of the four variables (availability and awareness,) investigated in the study. The mean score of the hospitals on the aggregate variable is presented in Table $4 \mathrm{a}$ below.

Table 4a Mean scores of the different hospitals on the aggregate variable

\begin{tabular}{lcccc}
\hline Hospitals & N & Mean & Std. Deviation & Std. Error \\
\hline FMC Makurdi & 66 & 2.70 & 0.336 & 0.041 \\
FMC Bida & 76 & 2.73 & 0.227 & 0.026 \\
FMC Birnin Kudu & 58 & 2.79 & 0.470 & 0.062 \\
FMC Katsina & 61 & 3.09 & 0.241 & 0.031 \\
ATBUTH Bauchi & 57 & 3.00 & 0.297 & 0.039 \\
FMC Yola & 57 & 3.34 & 0.212 & 0.028 \\
Total & 375 & 2.93 & 0.380 & 0.020 \\
\hline
\end{tabular}

Table 4a above shows the mean scores for the different hospitals which clearly showed that all the hospitals agreed that, there is availability and awareness, of the NASG. The observed significant variability is therefore on the magnitude of the scores by the different hospitals.

Table 4b.

Summary of ANOVA for the on availability, and awareness, of NASG by the hospitals

\begin{tabular}{lccccc}
\hline Source & Sum of Squares & DF & Mean Square & F & Sig. \\
\hline Between Groups & 19.159 & 5 & 3.832 & 40.629 & .000 \\
Within Groups & 34.801 & 369 & .094 & & \\
Total & 53.960 & 374 & & & \\
\hline \multicolumn{5}{l}{ P $<\mathbf{0 . 0 5}$ significance (F critical=2.21). }
\end{tabular}

Table 4b. above showed an $\mathrm{F}$ value of 40.629 which is greater than the critical value . The observed level of significance for the test is $0.000(\mathrm{P}<0.05)$. This means that the null hypothesis that there is no significant difference in the availability, and awareness, of NASG on PPH in tertiary hospitals of Northern Nigeria is therefore rejected.

To determine the hospital(s) that were significantly different from the other, a post hoc test was conducted on the mean using the Scheffe procedure. The result summary of the post hoc test is presented in Table $4 \mathrm{c}$ below.

Table 4c. Summary of Scheffe test on the means for the different hospital

\begin{tabular}{|c|c|c|c|c|}
\hline (I) Hospital & (J) Hospital & Mean Difference (I-J) & Std. Error & Sig. \\
\hline \multirow[t]{5}{*}{ FMC Makurdi } & FMC Bida & -.02849 & .05167 & .998 \\
\hline & FMC Birnin Kudu & -.08996 & .05527 & .754 \\
\hline & FMC Katsina & $-.38594(*)$ & .05454 & .000 \\
\hline & ATBUTH Bauchi & $-.30121(*)$ & .05553 & .000 \\
\hline & FMC Yola & $-.64206(*)$ & .05553 & .000 \\
\hline \multirow[t]{5}{*}{ FMC Bida } & FMC Makurdi & .02849 & .05167 & .998 \\
\hline & FMC Birnin Kudu & -.06146 & .05354 & .933 \\
\hline & FMC Katsina & $-.35744(*)$ & .05279 & .000 \\
\hline & ATBUTH Bauchi & $-.27271(*)$ & .05381 & .000 \\
\hline & FMC Yola & $-.61357(*)$ & .05381 & .000 \\
\hline \multirow[t]{5}{*}{ FMC Birnin Kudu } & FMC Makurdi & .08996 & .05527 & .754 \\
\hline & FMC Bida & .06146 & .05354 & .933 \\
\hline & FMC Katsina & $-.29598(*)$ & .05632 & .000 \\
\hline & ATBUTH Bauchi & $-.21125(*)$ & .05728 & .020 \\
\hline & FMC Yola & $-.55210(*)$ & .05728 & .000 \\
\hline \multirow[t]{5}{*}{ FMC Katsina } & FMC Makurdi & $.38594(*)$ & .05454 & .000 \\
\hline & FMC Bida & $.35744(*)$ & .05279 & .000 \\
\hline & FMC Birnin Kudu & $.29598(*)$ & .05632 & .000 \\
\hline & ATBUTH Bauchi & .08473 & .05657 & .814 \\
\hline & FMC Yola & $-.25612(*)$ & .05657 & .001 \\
\hline \multirow[t]{5}{*}{ ATBUTH Bauchi } & FMC Makurdi & $.30121(*)$ & .05553 & .000 \\
\hline & FMC Bida & $.27271(*)$ & .05381 & .000 \\
\hline & FMC Birnin Kudu & $.21125(*)$ & .05728 & .020 \\
\hline & FMC Katsina & -.08473 & .05657 & .814 \\
\hline & FMC Yola & $-.34085\left(^{*}\right)$ & .05753 & .000 \\
\hline \multirow[t]{5}{*}{ FMC Yola } & FMC Makurdi & $.64206(*)$ & .05553 & .000 \\
\hline & FMC Bida & $.61357(*)$ & .05381 & .000 \\
\hline & FMC Birnin Kudu & $.55210(*)$ & .05728 & .000 \\
\hline & FMC Katsina & $.25612(*)$ & .05657 & .001 \\
\hline & ATBUTH Bauchi & $.34085(*)$ & .05753 & .000 \\
\hline
\end{tabular}


* The mean difference is significant at the .05 level.

Table 4c. above showed that, Federal Medical Center, Makurdi have the least rating of the availability and awareness of the Non-Pneumatic Anti-shock Garment and were significantly different from the rating of respondents in Federal Medical Centers, Katsina, Bauchi and Yola. There was no significant difference between the rating of the variable between the Federal Medical Center, Makurdi, Birnin Kudu and that of Bida. Between Bida and Birnin Kudu, no significant difference was observed. The three centers Makurdi, Bida and Birnin Kudu had the lowest ratings. And between ATBUTH, Bauchi, FMC, Katsina and FMC, Yola, no significant difference was observed in their ratings of the garment.

\section{Sub-hypothesis I:}

There is no significant difference in the availability of NASG among tertiary hospitals of the three zones in Northern Nigeria. Only the scores on the availability of the garment in the different hospitals involved in the study were used as the dependent variable for this test. The mean scores of the different hospitals on the availability of the garment are presented in Table $5 \mathrm{a}$.

Table 4:2:2:2a: Means scores on availability of the NASG garments by the hospitals

\begin{tabular}{lcccc}
\hline Hospitals & $\mathrm{N}$ & Mean & Std. Deviation & Std. Error \\
\hline FMC Makurdi & 66 & 1.93 & .508 & .063 \\
FMC Bida & 76 & 1.85 & .498 & .057 \\
FMC Birnin Kudu & 58 & 1.80 & .780 & .102 \\
FMC Katsina & 61 & 2.88 & .378 & .048 \\
ATBUTH Bauchi & 57 & 2.54 & .363 & .048 \\
FMC Yola & 57 & 3.12 & .457 & .061 \\
Total & 375 & 2.32 & .729 & .038 \\
\hline
\end{tabular}

Table 5a above showed that the rating of availability by respondents from Federal Medical Centers, Makurdi, Bida and Birnin Kudu were below agreement mean of 2.50. But the ratings of Federal Medical Centers of Katsina, Bauchi and Yola were all above average.

The summary of the analysis of variance model obtained from the procedure used for the test of the hypothesis is presented in Table 4:2:2:2b below.

Table 5b. Summary of ANOVA for the on availability of NASG by the hospitals

\begin{tabular}{lccccc}
\hline Source & Sum of Squares & DF & Mean Square & F & Sig. \\
\hline Between Groups & 100.745 & 5 & 20.149 & 76.035 & .000 \\
Within Groups & 97.783 & 369 & .265 & & \\
Total & 198.528 & 374 & & \\
\hline \multicolumn{7}{c}{$\mathbf{P = 0 . 0 0 0}<\mathbf{0 . 0 5}$ Significance }
\end{tabular}

\section{$\mathbf{P}=\mathbf{0 . 0 0 0}<0.05$, Significance}

Table 4:2:2:2b above showed that, there is a significant difference in the rating of the availability of the garment in the different hospitals involved in the study $(\mathrm{P}<0.05)$. This means that the null hypothesis that there is no significant difference in the availability of NASG among tertiary hospitals of the three zones in Northern Nigeria is rejected.

The post hoc test (Scheffe procedure) used to differentiate the rating that was significantly different from the other is presented in Table $\mathbf{5 c}$ below.

Table 5c

Summary of Scheffe test on the mean scores of availability of NASG by hospital

\begin{tabular}{llccc} 
(I) Hospital & (J) Hospital & Mean Difference (I-J) & Std. Error & Sig. \\
\hline FMC Makurdi & FMC Bida & .075 & .087 & .980 \\
& FMC Birnin Kudu & .131 & .093 & .850 \\
& FMC Katsina & $-.954\left(^{*}\right)$ & .091 & .000 \\
& ATBUTH Bauchi & $-.610\left(^{*}\right)$ & .093 & .000 \\
FMC Bida & FMC Yola & $-1.189\left(^{*}\right)$ & .093 & .000 \\
& FMC Makurdi & -.075 & .087 & .980 \\
& FMC Birnin Kudu & .056 & .090 & .996 \\
& FMC Katsina & $-1.029\left(^{*}\right)$ & .088 & .000 \\
& ATBUTH Bauchi & $-.685\left(^{*}\right)$ & .090 & .000 \\
\hline
\end{tabular}




\begin{tabular}{|c|c|c|c|c|}
\hline & FMC Yola & $-1.264(*)$ & .090 & .000 \\
\hline \multirow[t]{5}{*}{ FMC Birnin Kudu } & FMC Makurdi & -.131 & .093 & .850 \\
\hline & FMC Bida & -.056 & .090 & .996 \\
\hline & FMC Katsina & $-1.085(*)$ & .094 & .000 \\
\hline & ATBUTH Bauchi & $-.741(*)$ & .096 & .000 \\
\hline & FMC Yola & $-1.320(*)$ & .096 & .000 \\
\hline \multirow[t]{5}{*}{ FMC Katsina } & FMC Makurdi & $.954(*)$ & .091 & .000 \\
\hline & FMC Bida & $1.029(*)$ & .088 & .000 \\
\hline & FMC Birnin Kudu & $1.085(*)$ & .094 & .000 \\
\hline & ATBUTH Bauchi & $.344(*)$ & .095 & .023 \\
\hline & FMC Yola & -.235 & .095 & .297 \\
\hline \multirow[t]{5}{*}{ ATBUTH Bauchi } & FMC Makurdi & $.610(*)$ & .093 & .000 \\
\hline & FMC Bida & $.685(*)$ & .090 & .000 \\
\hline & FMC Birnin Kudu & $.741(*)$ & .096 & .000 \\
\hline & FMC Katsina & $-.344(*)$ & .095 & .023 \\
\hline & FMC Yola & $-.579(*)$ & .096 & .000 \\
\hline \multirow[t]{5}{*}{ FMC Yola } & FMC Makurdi & $1.189(*)$ & .093 & .000 \\
\hline & FMC Bida & $1.264(*)$ & .090 & .000 \\
\hline & FMC Birnin Kudu & $1.320(*)$ & .096 & .000 \\
\hline & FMC Katsina & .235 & .095 & .297 \\
\hline & ATBUTH Bauchi & $.579(*)$ & .096 & .000 \\
\hline
\end{tabular}

* The mean difference is significant at the 0.05 level.

Table 5c above showed that FMC Makurdi, Bida and Birnin Kudu were all significantly different from FMC, Katsina, Yola and Bauchi. Between the three FMCs (Makurdi, Bida and Birnin Kudu) no significant difference was observed and between FMC Yola, ATBUTH Bauchi and Katsina, No significant difference was observed.

\section{Sub-hypothesis II:}

There is no significant difference in the awareness of NASG among tertiary hospitals of the three zones in Northern Nigeria. The test of this second sub-hypothesis was carried out with the use of the one way analysis of variance on the awareness rating by the hospitals. The mean scores of the hospitals on the awareness are presented in Table 6a.

Table 6a Mean scores on awareness of NASG garment by the hospitals

\begin{tabular}{lcccc}
\hline Hospitals & N & Mean & Std. Deviation & Std. Error \\
\hline FMC Makurdi & 66 & 2.94 & 0.422 & 0.052 \\
FMC Bida & 76 & 3.12 & 0.364 & 0.042 \\
FMC Birnin Kudu & 58 & 3.20 & 0.693 & 0.091 \\
FMC Katsina & 61 & 3.33 & 0.367 & 0.047 \\
ATBUTH Bauchi & 57 & 3.18 & 0.430 & 0.057 \\
FMC Yola & 57 & 3.37 & 0.336 & 0.044 \\
Total & 375 & 3.18 & 0.466 & 0.024 \\
\hline
\end{tabular}

Table 6a above showed that all the respondents from the hospitals agreed with the high level of awareness of the garment. Therefore the observed significant variability could be associated with the magnitude of the rating by the different respondents in the hospitals. 
Table 6b Summary of ANOVA for the on awareness of NASG by the hospitals

\begin{tabular}{lcccc}
\hline Source & Sum of Squares & DF & Mean Square & F \\
\hline Between Groups & 7.605 & 5 & 1.521 & 7.624 \\
Within Groups & 73.620 & 369 & .200 & .000 \\
Total & 81.225 & 374 & & \\
\hline
\end{tabular}

$\mathbf{P}=0.000<0.05$, Significance

Table 6b above the test showed that the hospitals differ significantly in their awareness of the NonPneumatic Anti-shock Garment for postpartum haemorrhage $(\mathrm{P}<0.05)$. By this observation, the null hypothesis that there is no significant difference in the awareness of NASG among tertiary hospitals of the three zones in Northern Nigeria is rejected. However, a post hoc test was conducted on the mean scores to determine the hospitals that were significantly different from the others in their awareness rating of the garment.

The result of the post hoc test to differentiate the hospitals that were significantly different from the others is presented in Table 6c.

Table 6c Summary of Scheffe procedure on awareness of NASG garment by the hospitals

\begin{tabular}{|c|c|c|c|c|}
\hline (I) Hospital & (J) Hospital & Mean Difference (I-J) & Std. Error & Sig. \\
\hline \multirow[t]{5}{*}{ FMC Makurdi } & FMC Bida & -.173 & .075 & .384 \\
\hline & FMC Birnin Kudu & -.256 & .080 & .074 \\
\hline & FMC Katsina & $-.391(*)$ & .079 & .000 \\
\hline & ATBUTH Bauchi & -.237 & .081 & .129 \\
\hline & FMC Yola & $-.430(*)$ & .081 & .000 \\
\hline \multirow[t]{5}{*}{ FMC Bida } & FMC Makurdi & .173 & .075 & .384 \\
\hline & FMC Birnin Kudu & -.083 & .078 & .951 \\
\hline & FMC Katsina & -.218 & .077 & .154 \\
\hline & ATBUTH Bauchi & -.064 & .078 & .985 \\
\hline & FMC Yola & -.257 & .078 & .058 \\
\hline \multirow[t]{5}{*}{ FMC Birnin Kudu } & FMC Makurdi & .256 & .080 & .074 \\
\hline & FMC Bida & .083 & .078 & .951 \\
\hline & FMC Katsina & -.135 & .082 & .741 \\
\hline & ATBUTH Bauchi & .019 & .083 & 1.000 \\
\hline & FMC Yola & -.174 & .083 & .500 \\
\hline \multirow[t]{5}{*}{ FMC Katsina } & FMC Makurdi & $.391(*)$ & .079 & .000 \\
\hline & FMC Bida & .218 & .077 & .154 \\
\hline & FMC Birnin Kudu & .135 & .082 & .741 \\
\hline & ATBUTH Bauchi & .154 & .082 & .620 \\
\hline & FMC Yola & -.039 & .082 & .999 \\
\hline \multirow[t]{5}{*}{ ATBUTH Bauchi } & FMC Makurdi & .237 & .081 & .129 \\
\hline & FMC Bida & .064 & .078 & .985 \\
\hline & FMC Birnin Kudu & -.019 & .083 & 1.000 \\
\hline & FMC Katsina & -.154 & .082 & .620 \\
\hline & FMC Yola & -.193 & .084 & .380 \\
\hline \multirow[t]{5}{*}{ FMC Yola } & FMC Makurdi & $.430(*)$ & .081 & .000 \\
\hline & FMC Bida & .257 & .078 & .058 \\
\hline & FMC Birnin Kudu & .174 & .083 & .500 \\
\hline & FMC Katsina & .039 & .082 & .999 \\
\hline & ATBUTH Bauchi & .193 & .084 & .380 \\
\hline
\end{tabular}

* The mean difference is significant at the 0.05 level.

From table $6 \mathrm{c}$ only significant difference observed in the mean scores was between FMC Makurdi and FMC Yola. Between the other hospitals as indicated in the table no significant difference was observed. And The rating of FMC Makurdi was not significantly different from FMC ATBUTH Bauchi, FMC Birnin Kudu and Bida. As earlier observed, the differences are basically on the level of rating but there was no disagreement between respondents from the different hospitals on the awareness of the garment.

\section{Discussion}

The study assessed the availability, awareness, utilization and effectiveness of the NASG for postpartum haemorrhage among tertiary hospitals in Northern Nigeria. The rated scores of the respondents from the different hospitals revealed that Doctors and Nurses were aware of the garment but the availability differs between the hospitals. From comparative analysis on availability of the NASG, it was revealed that FMC Makurdi, FMC Birnin Kudu, FMC Bida were particularly affected by the non-availability of the garment. From the test of the major hypothesis, It was observed that hospitals differed significantly in the availability, awareness, utilization and effectiveness of the garment for the reduction of postpartum haemorrhage among patients. The null hypothesis was therefore rejected. 
In the test of the first sub-hypothesis, it was observed that some significant variability existed in the level of availability of the garment in the different hospitals. The hospitals particularly affected by this nonavailability of the garment were Makurdi, Bida and Birnin Kudu. The statistical analysis of the data collected for the study revealed that non-pneumatic anti-shock garment (NASG) is available within the tertiary hospitals in Northern Nigeria but strictly under the control of the hospitals' management. However, there was variability in this assumed availability because some of the hospitals like Makurdi, Bida and Birnin Kudu scored very low ratings of the garment in their respective hospitals. The assumed availability of the garment which though under the strict control of the hospitals' management is based on the agreed awareness, utilization and the effectiveness which the respondents agreed were adequate in their respective hospitals. Therefore it could be said that the garment is not available in the open society of the studied area at the time of this survey.

The finding here agrees with Ojengbede (2006) who stated that the NASG is not yet available in the open market but in some designated health centers through the efforts of the government and Pathfinder International. The result of the study contradicts Wilder (2009) who states that Pathfinder equips secondary and tertiary health facilities of which the Tertiary hospitals are supposed to be part.

Considering the maternal mortality in some state of the Federation, the availability of the NASG garment is something that aught to be encouraged into the open society. For example, it is estimated that maternal mortality in Northern Nigeria is very high. It is well over 1000/100,000 life birth (NDHS, 2008). ADSEEDS, (2007) stated that Adamawa has a maternal mortality rate of $2000 / 100,000$ live births, Jigawa state has maternal mortality rate of 2000/100,000 live births (Magashi, 2012), Kano state has maternal mortality rate of 1,600/100,000 live births (Galadanci, Idris, Sadauki \& Yakasai, 2010), Benue has maternal mortality rate of 1000/100,000 live births (Mohammed, 2013). Katsina has maternal mortality rate of 927/100,000 live births (Fawole, 2012), Niger state has maternal mortality rate of 548/100,000 live births (Ibrahim, 2012 \& Bauchi state has maternal mortality rate of 1549/100,000 live births (USAID, 2013). It will not be acceptable to say that the NASG is not available in this region of the country. In view of the fact that it is estimated that $34 \%$ of maternal mortality are caused by postpartum haemorrhage (WHO, 2010).Reduction of maternal mortality in this region will require availability of the non-pneumatic Anti-shock garment in all hospitals in addition to other strategies.

It was also observed in the study that awareness level of the doctors and Nurses in the hospitals concerning the NASG garment was very high. In the test of the second sub-hypothesis of the study, significant variability was observed in the test. However, the observed means scores from the test revealed that the observed variability has more to do with the degree of responsiveness to the awareness of the garment in the hospitals than a divergence of opinion. This result is rather encouraging because of the promising effect of NASG on the reduction of postpartum haemorrhage, the resuscitation of women with obstetric shock and its reduction of maternal mortality. Though there was significant variability in the rating of the awareness levels but the overall perceptions was encouraging because all the respondents were aware of the NASG in the hospitals. This finding is line with Wilder (2009), who stated that the Pathfinder concentrates on training of providers on NASG in most health centres. The finding is agreement with Pathfinder (2011) where it was reported that it has implemented training activities in seven states of Nigeria which include Kano, Katsina, Oyo, Lagos, Nasarawa, Ebonyi and Yobe. It also shows that the training programmes have built the awareness of the nurses and doctors. Training or awareness creation is expected to be supported with supply of the NASG in the health facilities .The awareness of the NASG by doctors and nurses of the tertiary hospitals is important looking at their roles as trainers of health manpower for the purpose of stepping down the knowledge to their trainee. Looking at responses to questionnaire items, the result reveal an aggregate mean score of 2.63 for question item 5 (you have had training on the NASG ) this score means that almost half of the respondents did not have training, their awareness can be attributed to personal effort . Training need to extend to the whole region not merely selected states.

The result from the test of sub-hypothesis three revealed that doctors and nurses in the selected tertiary hospitals adequately utilize the NASG for the management of postpartum haemorrhage. There was however some significant variability in this observation. From the mean scores of the different from the hospitals, it was observed that differences between the groups were merely on the basis of ranking and that all of them agreed with the utilization of the garment in the hospitals. This finding is very encouraging because the garment holds high promise in the reduction of maternal death by reducing bleeding and also revitalizing women with obstetric shock. The result of the study agrees with Wilder (2009) who stated that in Nigeria, 31 facilities use the NASG. Clinical trials by Mou-rad-yussif et al. (2010) carried out in Nigeria might have not included the tertiary hospitals used for this study but indication from this study clearly shows that the tertiary hospitals as well uses the garment.

The finding here collaborates the studies by Wilder (2009) and the advocacy of utilization of NASG for postpartum haemorrhage by SOGON (2010) and Pathfinder (2011). The unavailability of the NASG in the wider society however has become a clear barrier to the effective wider utilization of the NASG for postpartum haemorrhage. 


\section{Conclussion}

On the basis of the results obtained from this study, the following conclusions were drawn:NASG is available in some of the selected hospitals but strictly within the control of the hospitals' management in Northern Nigeria. Nurses and doctors in tertiary hospitals in Northern Nigeria are aware of the NASG for postpartum haemorrhage. There is significant difference in the availability, awareness, utilization and perception of effectiveness of the NASG for postpartum haemorrhage among nurses and doctors of the selected tertiary hospitals in Northern Nigeria.

\section{Recommendations}

On the basis of the findings of the study, the following recommendations were made:

1. Government should make the Non-Pneumatic Antishock garment (NASG) available in all hospitals in Northern Nigeria.

2. Doctors and nurses should find modalities of stepping down the training of Non-Pneumatic Antishock garment (NASG) to ensure adequate utilization.

\section{References}

[1]. Adamawa State Economic Empowerment (2007). Health status situation analysis. Adamawa state SEEDS document final draft. retrieved on 05/08/2012. From http://www.ng.undp.org/document/seeds/Adamawa_state.pdf.

[2]. Bressa, C, Hensleigh P.A \& Peligra R.A. (2004). A non-inflamable anti-shock garment for obstetric haemorrhage. International Journal of Gynaecology and obstetric, 87(2):119-124

[3]. Fawole, A.O., Shah, A., Fabanwo, AO., Adegbola, O., Adewumi, A.A., Eniayewun, A.B., Dara, K.,El- Ladan, A.M. \& Sa'id, M. (2012). Predictors of maternal mortality in institutional deliveries in Nigeria. African Health Sciences. www.ncbi.nlm.nih.gov/pmc/articles/pmc3462508.

[4]. Galadanci, H.S., Idris, S.A. Sadauki, H.M. \& Yakasai, I.A. (2010). Programmes and policies For reducing maternal mortality in Kano state Nigeria: A review , African Journal of Reproductive Health,14(3):31.

[5]. Hensleigh, P.A. (2002). Antishock garment provides resuscitation and haemostasis British journal of Obstetric and Gynaecology,109(12)1377-84.

[6]. ICM/FIGO. (2010).Joint Statement: Management of the Third Stage of Labour to Prevent Postpartum Haemorrhage. Available from: http://www.pphprevention.org

[7]. Ijaiya, M., Aboyeji , A.P. \& Abubakar, D. (2003). Analysis of 384 consecutive cases of primary Post Partum Haemorrhage at a tertiary hospital in Nigeria. Journal of obstetric Gyneacol 23:374-377.

[8]. Isaac \& Michael (1981); Smith, (1983), Sample size selection chart. Retrieved On 03/04/2012 from http://www.uwex.edu/ces/resources

[9]. Jadesimi, A. \& Okonofua , F.E (2006), Tackling the unacceptable: Nigeria approves misoprostol for postpartum haemorrhage. Journal of Family Planning and Reproductive Health Care. 2006 Oct; 32(4):213-214.

[10]. Kenlinger, F.N. (1986). Foundation of behavioural research, $3^{\text {rd }}$ edition London: Williams Clowes and sons limited. pp. 97.

[11]. Khan, K.S, Wojdyla, D., Say L., Ghumezoghue, M. \& Van Look, P.F. (2006): "WHO analysis of Causes of Maternal Death: a Systematic Review." Lancet, 1066 - 1074.

[12]. Kullami, A.A., Kawuwa, M.B., Audu, B.M.,Geidam, A.D., \& Mairiga, A.G. (2009). Trends in Maternal Mortality In a Tertiary Institution In Northern Nigeria: retrieved on 08/06/2010, from http://annalssfrmed.org/article.asp.

[13]. McCarthy, I. \& Maine, D. (1992). A framework for analysing the determinant of Maternal Mortality. Stud fam plan, 23:23-33. www.pubmedAbstract/publisherfulltext.

[14]. Miller, S., Ojengbede, O., Turan, J., Morhason-Bello, I.O., Martin, B.H. \& Nsima, D. (2009). A Comparative study of the nonepneumatic anti-shock garment for the treatment of Obstetric haemorrhage in Nigeria. International Journal of Gynaecology and Obstetrics, retrieved on 08/06/2010, from www.elsevier.com/locate/ijgo.

[15]. Miller, S., Fattavla, M., Yousif, M., Turan, J., Carilin, C., Al-Hussaini, T. \& Meyer, C. (2010). Obstetric haemorrhage and shock management: using the low technology Non-pneumatic anti-shock garment in Nigeria and Egyptian tertiary care facilities. International journal of Gynaecology and obstetric http://biomedcentral.com/1471-2393/10/64.

[16]. Miller, S., Martin, B.H., \& Morris ,L.J. (2008). Anti-shock garment in postpartum haemorrhage. Best practice and research clinical Obstetrics and gynaecology 22,( 6),pp 1057-1074.

[17]. Miller, S., Turan, J., Dau, K., Fathalla, M., Mourad, M., Sutherland, T., ....., Gipson, R. (2007). Use of the non-pneumatic antishock garment (NASG) to reduce blood loss and time to recovery from shock for women with obstetric haemorrhage in Egypt. Global Public Health 2007, 2:110-124.

[18]. Mohamed, A. (2013). NPHCDA "Markurdi records 60,000 annual maternal deaths" Vanguard news paper $26^{\text {th }}$ march 2013. www.vangurd.com/2013/03.

[19]. Mourad-Youssif, M., Ojengbede, O., Meyer C., Fathalla, M., Morhason-Bello I.O., Galadanci, H. \& Miller,

[20]. S. (2010). Can the Non-pneumatic anti-shock garment (NASG) Reduce adverse maternal out comes

[21]. from postpartum haemorrhage? Evidence from Egypt and Nigeria. Journal of Reproductive Health,

[22]. 7:24, Retrieved on 05/01/2011 from http://www.reproductive-health-journal.com

[23]. National Bureau of Statistics (2010). The review of the Nigeria economy 2010 retrieved on 08/05/2010 from http://www.nigerianstat.gov:ng

[24]. Nworgu, B.G. (1991). Educational research: Basic issues \& Methodology. Wisdom publishers, Nigeria, pg.157.

[25]. National Demographic Health Survey (2008). Maternal Health reports, Abuja, Nigeria.

[26]. Ojengbede O., Miller S., Morhason Bello I .O. Turan J., Dau K., McDonough L., Fabamwo A, Hensleigh, P. (2006) "An Analysis of haemorrhage reduction and improved recovery among patients with hypovolemic shock secondary to postpartum and post abortion haemorrhage: A pilot study of the NASG in Nigeria." Abstract for FIGO 2006 Kuala Lumpur. http://www3.utsouthwestern.edu.

[27]. Ojengbede ,O., Turan, J., Galadanci, H., Morhason-Bello, I., Duro-Aina, T. \& Fabamwo, A. (2008).Use of the Non-pneumatic Anti-Shock Garment for Treatment of Obstetric Haemorrhage. Society of Gynaecology and Obstetrics of Nigeria (SOGON) Annual Conference; November; Ibadan, Nigeria. 
[28]. Ojengbede, A.,O, Morhason-Bello, I.O., Galadanci, H., Meyer, C., Nsima, D., Camlin, C., Butric, E., \& Miller, S. (2011). Assessing the role of the Non-pneumatic Anti-shock garment in reducing mortality from postpartum haemorrhage in Nigeria. $\begin{array}{llllll}\text { Gynaecology and Obstetric investigations } & 07(1): 66-72 \text {. Retrieved on } 01 / 05 / 2011 . & \text { from }\end{array}$ http://content.karger.com/produkteDB/produdute.asp?

[29]. Oshonowo , P.(2007). In Pathfinder (2011) Community and clinical action to address postpartum haemorrhage. Retrieved on 5/09/2012 From http://www.nlm.nih.gov/medlineplus/ency/article/003133.htm.

[30]. Pathfinder international (2007). Preventing PPH: managing the third stage of labour. PATH, Outlook. 19(3).

[31]. Pathfinder (2011) Community and clinical action to address postpartum haemorrhage. Retrieved on 5/09/2012 From http://www.nlm.nih.gov/medlineplus/ency/article/003133.htm.

[32]. Roscoe, J .T. (1969)_Fundamental Research Statistics for_Behavioral Sciences. New York,

[33]. Halt, Rinehart and Winston, Inc.

[34]. Thadius S \& Mine, D. (1994). Too far walk: Maternal mortality in context, social science medicine, London birth press AVON 38:1091-1110.2004,363:75-76, www.pubmedAbstract/publisherfulltext.

[35]. USAID. (2011). Maternal and Child Health: Nigeria. Accessed on April 11 , 2011. http://www.usaid.gov/our_work/global_health/mch/mh/countries/nigeria.html.

[36]. USAID. (2013).Nigeria Targeted States High Impact. Retrieved on May 10, 2013. From www.jsi.com/JSIIntret/IntlHealth/project/display.cfm?

[37]. UNICEF \& USAID (2010). Mother, New born \& child health\& mortality status. Northern states in Nigeria. Accessed on April 8, 2011. http://www.unicef.org/infobycountry/nigeria_statistics.html

[38]. Wilder, J. (2009). Global health magazine, retrieved on 08/04/2012 from

[39]. http://www.globalhealthmagazine.com.

[40]. World Health Organisation. (2010). Trends in maternal mortality: 1990-2008. Estimates of maternal mortality.

[41]. World Health Organisation (2000) Managing Complications in pregnancy and childbirth: a guide for midwives and Doctors. WHO/RHR/00.7.

[42]. WHO, UNICEF, UNFPA \& World Bank (2012). Trends in maternal mortality: 1990-2010 Estimates of maternal mortality. European women's lobby retrieved on 02/08/2012 from http://www.unfpa.org. 